\title{
ARTIGO CIENTÍFICO \\ Crescimento inicial do milho sob doses de esterco caprino e disponibilidade de água no solo
}

\author{
Initial growth of maize under manure goat doses and water availability in soil \\ Francisco Marto de Souza ${ }^{1 *}$, Ellen Caroline Santos Lima ${ }^{2}$, Francisco Vanies da Silva Sá ${ }^{3}$, Lauter Silva Souto ${ }^{4}$, Jonathan
Estivens Soares Araújo ${ }^{5}$ Emanoela Pereira de Paiva ${ }^{6}$
}

Resumo: Objetivou-se estudar a emergência e o crescimento inicial de plantas de milho adubadas com esterco caprino sob dois regimes de disponibilidade de água no solo. $\mathrm{O}$ arranjo dos tratamentos constituiu um fatorial 4 x 2, correspondentes a quatro doses de esterco caprino ( $0,4,8$ e $\left.12 \mathrm{t} \mathrm{ha}^{-1}\right)$ e dois níveis de água disponível de 50 e $100 \%$ da capacidade de campo, mantido após as irrigações do solo, com 8 tratamentos e quatro repetições, totalizando as 32 unidades experimentais. O ensaio foi realizado em unidades experimentais compostas por vasos de $18 \mathrm{dm}^{3}$ de capacidade, semeando manualmente quatro sementes por vaso. As plantas foram conduzidas por 20 dias após a semeadura, sendo avaliadas quanto à emergência, 0 crescimento inicial e o acúmulo de massa seca. A redução de 50\% de água no solo não exerce impactos negativo sobre a emergência e crescimento inicial das plantas de milho AG1051. A dose de esterco caprino de $12 \mathrm{t} \mathrm{ha}^{-1}$ promoveu o maior crescimento e acúmulo de massa seca das plantas de milho.

Palavras-chave: Zea mays; Adubação orgânica; Irrigação

\begin{abstract}
The objective was to study the emergence and initial growth of corn plants fertilized with goat manure under two water availability regimes in soil. The treatment arrangement consisted of a $4 \times 2$ factorial, corresponding to four doses of goat manure $\left(0,4,8\right.$ and $\left.12 \mathrm{t} \mathrm{ha}^{-1}\right)$ and two levels of available water of 50 and $100 \%$ of field capacity, maintained after The soil irrigations, with 8 treatments and four replications, totalizing the 32 experimental units. The experiment was carried out in experimental units composed of pots of $18 \mathrm{dm}^{3}$ of capacity, manually seeding four seeds per pot. The plants were conducted for 20 days after sowing, where they were evaluated for emergence, initial growth and dry mass accumulation. The reduction of $50 \%$ of water in the soil does not have a negative impact on the emergence and initial growth of AG1051 maize plants. The dose of goat manure of $12 \mathrm{tha}^{-1}$ promoted the highest growth and accumulation of dry mass of maize plants.
\end{abstract}

Key words: Zea mays, organic fertilization, irrigation.

\footnotetext{
*Autor para correspondência

Recebido para publicação em 20/01/2017; aprovado em 27/05/2017

${ }^{1}$ Mestrando em Ciência do Solo, Universidade Federal da Paraíba-UFPB, Areia, PB; Fone: (83)99901-4983, E-mail: francisco.marto@ hotmail.com

${ }^{2}$ Graduação em Agronomia , Universidade Federal de Campina Grande-UFCG, E-mail: ellencaroline.s1@ @otmail.com

${ }^{3}$ Doutorando em Engenharia Agrícola , Universidade Federal de Campina Grande-UFCG, E-mail: vanies_agronomia@hotmail.com

${ }^{4}$ Professor Doutor, Universidade Federal de Campina Grande-UFCG, E-mail: lautersouto@ yahoo.com.br

${ }^{5}$ Graduação em Agronomia , Universidade Federal de Campina Grande-UFCG, E-mail: jonathan.estivens @ hotmail.com

${ }^{6}$ Doutoranda em Fitotecnia, Universidade Federal Rural do Semi-Árido-UFERSA, E-mail: emanuelappaiva@ hotmail.com
} 


\section{INTRODUÇÃO}

O milho (Zea mays L.) é uma monocotiledônea, pertence à família Poaceae, esta espécie é nativa das américas, e se destaca como o cereal está entre os mais consumidos do mundo (SILOTO, 2002; LERAYER, 2006). A sua produção está voltada para a fabricação de ração e ao consumo de animais, sendo apenas uma pequena parcela consumida pelo homem. No Brasil o milho é cultivado em todos os estados do país, sendo que na região Norte e Nordeste grande parte desses cultivos é como cultura de subsistência, servindo de alimento e renda para agricultores familiares.

Segundo Castro (2013), o Nordeste do Brasil possui problemas relacionados a sustentabilidade dos sistemas de produção de alimentos, inerentes aos efeitos do clima, como a seca, pois é um dos principais fatores que limitam a produção. A cultura do milho, apesar de possuir como característica resistência as intempéries do clima, a sua produtividade pode ser comprometida em condições de déficit hídrico, sobretudo no período crítico da cultura (BERGONCI et al., 2001).

Por possuir a capacidade de reter água em até 20 vezes o seu peso seco (STEVENSON, 1982), a matéria orgânica se torna uma forte aliada em sistemas de produção agrícola que possuem baixa disponibilidade hídrica, pois está além de fornecer nutrientes, acaba armazenando água que pode ser usada pelas plantas durante o período de escassez. Kiehl (1979) encontrou resultados que confirmam que há correlação entre a quantidade de matéria orgânica e a quantidade de água armazenada.

Além da sua utilização como atenuador do estresse hídrico o esterco pode ser uma alternativa na produção vegetal, pois reduz os custos de produção por ser mais barato que os fertilizantes sintéticos e os substratos comerciais (BRUGNARA, 2014), além de melhorar os atributos físicos, químicos e biológicos do solo (PEREIRA et al., 2013). A deficiência de natural de $\mathrm{N}$ e $\mathrm{P}$ nos solos do Nordeste faz com que a produção agrícola seja limitada, caso não haja outra forma de suprir as necessidades das culturas (GALVÃO et al., 2008). Diante disso, torna-se necessário o uso de formas alternativas de recuperação da fertilidade natural do solo, para que haja base de sustentação para o sistema produtivo e equilíbrio ecológico (FERREIRA et al., 2010).

$\mathrm{O}$ uso do esterco caprino é uma forma de melhor aproveitamento dos estercos gerados no meio rural, uma vez que os mais comumente usados são os de cama de aviário e o bovino, talvez por falta de conhecimento do seu potencial produtivo. Para Melo et al. (2009) no Nordeste brasileiro, sobretudo no Semiárido, o uso de esterco caprino não é uma prática comum, mesmo sendo a caprinocultura uma substancial fonte de renda para a região. Ainda segundo o autor, esse fato se deve fato do produtor vender os estercos como forma de complementar a renda da família, como também, por falta de conhecimento sobre sua importância.

Com isso, objetivou-se estudar a emergência e o crescimento inicial de plantas de milho adubadas com esterco caprino sob dois regimes de disponibilidade de água no solo.

\section{MATERIAL E MÉTODOS}

O experimento foi conduzido em condições de ambiente protegido (túnel plástico) na Universidade Federal de Campina Grande, Campus Pombal, de Dezembro de 2014 a janeiro de 2015. O município está localizado geograficamente na longitude $37^{\circ} 48^{\prime} 06^{\prime} \mathrm{W}$ e latitude $06^{\circ} 46^{\prime} 13^{\prime \prime} \mathrm{S}$, com altitude média de 184 metros. O clima de Pombal, baseado no sistema de classificação internacional de Köppen, foi incluído no tipo Bsh (semiárido) quente e seco, com chuvas de verão e outono e a precipitação pluviométrica média anual de 800 $\mathrm{mm}$, com variabilidade interanual, sendo os meses de fevereiro, março e abril os que mais chovem, concentrando 60 a $80 \%$ do total da precipitação anual. Possui temperaturas médias mensais variando de 23,40 a $27,90^{\circ} \mathrm{C}$ com máximas mensais de $35,70^{\circ} \mathrm{C}$ em dezembro, e mínimas de $19,30^{\circ} \mathrm{C}$, em julho e agosto.

$\mathrm{O}$ arranjo dos tratamentos constituiu um fatorial $4 \times 2$, correspondentes a cinco doses de esterco caprino (0, 4, 8 e 12 $\mathrm{t} \mathrm{ha}^{-1}$ ) e dois níveis de água disponível (AD) de 50 e $100 \%$ da capacidade de campo (CC), mantido após as irrigações do solo, com 8 tratamentos e quatro repetições, totalizando as 32 unidades experimentais.

$\mathrm{O}$ ensaio foi realizado em unidades experimentais compostas por vasos de $18 \mathrm{dm}^{3}$ de capacidade, semeando manualmente quatro sementes por vaso. O solo classificado como Neossolo Flúvico Eutrófico, apresentou, nos primeiros $20 \mathrm{~cm}$ de profundidade, 661, 213 e $126 \mathrm{~g} \mathrm{~kg}^{-1} \mathrm{de}$ areia, silte, argila; densidade do solo e de partículas, $1,51 \mathrm{e} 2,76 \mathrm{~g} \mathrm{~cm}^{-3}$, respectivamente, com porosidade total de $0,45 \mathrm{~m}^{3} \mathrm{~m}^{-3}$. Os valores da umidade na capacidade de campo, ponto de murchamento permanente e água disponível foram 23,52; 7,35 e $16,17 \%$, respectivamente. Quanto à caracterização química, do solo na mesma profundidade e da esterco caprino foi determinada conforme as metodologias de Embrapa (2011) (Tabelas 1 e 2).

Tabela 1. Características químicas dos componentes do solo usados no experimento na Universidade Federal de Campina Grande, Campus Pombal, Paraíba

\begin{tabular}{|c|c|c|c|c|c|c|c|c|c|c|c|}
\hline $\begin{array}{c}\mathrm{CE} \\
\mathrm{dS} \mathrm{m}{ }^{-1}\end{array}$ & $\begin{array}{c}\mathrm{pH} \\
\mathrm{H}_{2} \mathrm{O}\end{array}$ & $\begin{array}{c}\mathrm{P} \\
\mathrm{mg} \mathrm{dm}^{-3}\end{array}$ & $\mathrm{~K}^{+}$ & $\mathrm{Ca}^{+2}$ & $\mathrm{Mg}^{+2}$ & $\mathrm{Na}^{+}$ & $\begin{array}{l}\mathrm{Al}^{3+} \\
l_{c} \mathrm{dm}^{-3}\end{array}$ & $\mathrm{H}^{+}+\mathrm{Al}^{3+}$ & SB & $\mathrm{T}$ & $\begin{array}{c}\mathrm{MO} \\
\mathrm{g} \mathrm{kg}^{-3}\end{array}$ \\
\hline 0,09 & 8,07 & 3,00 & 0,32 & 6,40 & 3,20 & 0,18 & 0,00 & 0,00 & 10,49 & 10,49 & 16,0 \\
\hline
\end{tabular}

$\mathrm{SB}=$ soma de bases; $\mathrm{CE}=$ condutividade elétrica; $\mathrm{T}$ = capacidade de troca de cátions total; $\mathrm{M} . \mathrm{O}=$ matéria orgânica; $\mathrm{A}=\mathrm{Solo}$; $\mathrm{B}=$ substrato comercial.

Tabela 2. Caracterização química do esterco caprino utilizado como fonte de matéria orgânica em experimento na Universidade Federal de Campina Grande, Campus Pombal, Paraíba

\begin{tabular}{|c|c|c|c|c|c|c|c|c|c|c|c|c|}
\hline $\mathrm{N}$ & $\mathrm{P}$ & $\mathrm{K}$ & $\mathrm{Ca}$ & $\mathrm{Mg}$ & $\mathrm{Na}$ & $\mathrm{Zn}$ & $\mathrm{Cu}$ & $\mathrm{Fe}$ & Mn & MOS & $\mathrm{CO}$ & $\mathrm{C} / \mathrm{N}$ \\
\hline . & $\mathrm{g} \mathrm{kg}^{-1}$. & $\cdots$ & & & & $\ldots \ldots \ldots$ & $\mathrm{gg} \mathrm{kg}$ & & & $\ldots . \mathrm{g} \mathrm{kg}^{-1}$ & & \\
\hline 12,76 & 2,57 & 16,79 & 15,55 & 4,02 & 5,59 & 60 & 22 & 8550 & 325 & 396,0 & 229,7 & 18:1 \\
\hline
\end{tabular}

$\mathrm{CO}=$ Carbono orgânico; $\mathrm{CTC}=$ Capacidade de troca de cátions. 
As irrigações foram realizadas diariamente com um volume uniforme de água $\left(\mathrm{Ce}_{\mathrm{a}}=0,3 \mathrm{dS} \mathrm{m}^{-1}\right)$, em função da evapotranspiração média no tratamento testemunha, obtida por pesagem. O volume aplicado (Va) por recipiente foi obtido pela diferença entre a média do peso dos recipientes em condição de máxima retenção de água $\left(\mathrm{P}_{\mathrm{cc}}\right)$, o qual foi determinado saturando-se os recipientes com água e submetendo-os à drenagem; quando o volume drenado estabilizou os recipientes foram pesados, obtendo-se com isso, o valor do $\mathrm{P}_{\mathrm{cc}}$, ou seja o peso dos recipientes na máxima capacidade de retenção de água; e o peso médio dos recipientes na condição atual $\left(\mathrm{P}_{\mathrm{a}}\right)$, dividido pelo número de recipientes (n) (Equação 1).

$$
V a=\frac{P c c-P a}{n}
$$

Foram semeadas dez sementes de milho da cultivar AG 1051 em cada vaso à uma profundidade de $2 \mathrm{~cm}$, onde a emergência das plântulas e o crescimento inicial das plantas foram avaliados durante 15 dias após a semeadura (DAS). Durante a condução do experimento a emergência das plantas de milho foi monitorada por meio de contagens do número de plântulas emergidas, ou seja, com os cotilédones acima do nível do solo, foram realizadas diariamente, sem que estas fossem descartadas, obtendo-se, portanto, um valor cumulativo. Dessa maneira, o número de plântulas emergidas referentes a cada contagem foi obtido subtraindo-se do valor lido com o valor referente à leitura do dia anterior. Dessa forma, com o número de plântulas emergidas referentes a cada leitura, obtido em casa de vegetação, foi calculado o índice de velocidade de emergência (IVE), empregando a equação 2 descrita por Schuab et al. (2006).

$$
\text { IVE }=\frac{G_{1}}{N_{1}}+\frac{G_{2}}{N_{2}}+\cdots+\frac{G_{n}}{N_{n}}
$$

Em que: IVE = índice de velocidade de emergência; $\mathrm{G}=$ número de plântulas emergidas observadas em cada contagem; $\mathrm{N}=$ número de dias da semeadura a cada contagem.

Após a estabilização da emergência, foi determinada a percentagem de emergência (PE) (\%), obtida pela relação entre o número de plantas emergidas e o número de sementes plantadas.

Para a monitoração dos aspectos morfológicos da cultura, foi realizada análise de crescimento das plântulas aos 20 DAS, foi feita com a determinação da altura de planta (AP) $(\mathrm{cm})$, medida com uso de uma régua graduada pela distância entre o solo e o ápice da planta, do diâmetro do colmo (DC), medido com paquímetro digital, a um centímetro da superfície do solo e pela contagem do número de folhas (NF), a partir da contagem das folhas maduras. Ao fim da análise de crescimento, as plantas foram coletadas, separando-se a parte aérea das raízes e acondicionadas em estufa de circulação de ar à $65^{\circ} \mathrm{C}$, para secagem do material, após atingir massa constante, foram pesados em balança analítica determinando-se, com isso, a massa seca da parte aérea (MSPA) (g), e da raiz (MSR) (g). De posses desses dados, foi determinada a massa seca total (MST) por meio do somatório da MSPA e da MSR. E a relação raiz/parte aérea (RRPA) pela divisão da MSR pela MSPA.

Os efeitos das doses de esterco caprino (D), dos níveis de água disponível $(\mathrm{AD})$ e da interação $\mathrm{D}$ Versus $\mathrm{AD}$ foram avaliados estatisticamente, através da análise de variância de acordo com o teste $\mathrm{F}$, em caso de significância efetuou-se teste de Tukey, $\mathrm{p}<0,05$, para o fator níveis de água disponível e análise de regressão, $\mathrm{p}<0,05$, para o fator doses de esterco caprino e para in interação $\mathrm{D}$ Versus $\mathrm{AD}$, com auxílio do programa estatístico SISVAR 4.1 (FERREIRA, 2011).

\section{RESULTADOS E DISCUSSÃO}

Observou-se influencia $(\mathrm{P}<0,05)$ das doses (D) de esterco caprino nas variáveis analisadas: altura de plantas (AP), diâmetro do caule (DC), massa seca da parte aérea (MSPA), massa seca da raiz (MSR), massa seca total (MST), e da água disponível (AD) sobre a altura de planta. Não houve efeito significativo entre as variáveis: percentagem de emergência (PE), índice de velocidade de emergência (IVE), número de folhas (NF), e relação raiz/parte aérea. Possivelmente não houve diferença entre a (PE) e o (IVE) devido à pouca necessidade de manejo que a semente precise logo após a sua semeadura. Acrescenta-se a esse fator, a alta qualidade da semente utilizada, o que garante uniformidade e qualidade do plantio. Provavelmente a demanda hídrica da cultura foi suprida durante o período de avaliação, não implicando em diferença dos tratamentos. Com base em estudos realizados por Schittenhelm (2010), o milho apresenta capacidade de produzir mesmo havendo redução da disponibilidade hídrica.

Verificou-se que não houve interação entre as doses e a água disponível $\left(\mathrm{D}^{*} \mathrm{AD}\right) \quad(\mathrm{P}<0,05)$ das plantas de milho avaliadas aos 20 dias após a emergência (DAE). É possível que as condições de solo, umidade e esterco tenham favorecido de forma plena o crescimento inicial das plantas de milho, uma vez que nesta fase não há requerimento expressivo da planta por água e nutrientes.

Para as variáveis altura de planta (AP) e diâmetro do colmo (DC) observou-se comportamento linear crescente, o que implica dizer que a dose de $12 \mathrm{t} \mathrm{ha}^{-1}$ foi a que obteve resultados mais expressivos. Para essas varáveis constatou-se um incremente unitário de $0,2629 \mathrm{~cm}$ e $0,1085 \mathrm{~mm}$ para a AP e DC, que corresponde ao incremento de $3,15 \mathrm{~cm}$ e $1,3 \mathrm{~mm}$, respectivamente ao compara a maior $\left(12 \mathrm{t} \mathrm{ha}^{-1}\right)$ e a menor dose estudada (Figura 1A e C).

A rápida resposta de crescimento inicial das plantas de milho pode estar associada a estreita relação $\mathrm{C} / \mathrm{N}$ do esterco caprino, que apresentou valor de 18:1. Estercos que possuem relação $\mathrm{C} / \mathrm{N}$ abaixo de $20: 1$, fornece de maneira rápida os nutrientes necessários ao crescimento das plantas, sobretudo o N. Com base em Costa et al. (2007) material com relação C/N alta prejudica o fornecimento de $\mathrm{N}$ às plantas.

Em relação à altura de planta e água disponível (Figura 1B), nota-se que a redução da lâmina de água de $100 \%$ para $50 \%$ fez com que houvesse diminuição de $14,98 \%$ da altura das plantas. Foi observado que a água disponível (AD) influenciou em apenas a variável altura de planta (AP). Esse fato pode estar associado a possibilidade de maior crescimento e expansão das células vegetais, devido à alta disponibilidade hídrica na lâmina de $100 \%$, o que impulsiona a planta a crescer e desenvolver com maior rapidez. Segundo Ferrari et al. (2015) se o solo apresentar baixa disponibilidade de água, ocorrerá diminuição das taxas de crescimento, de matéria seca e expansão celular. 
Figura 1. Altura (A e B) e Diâmetro do colmo (C) de plantas de milho sob doses de esterco caprino.
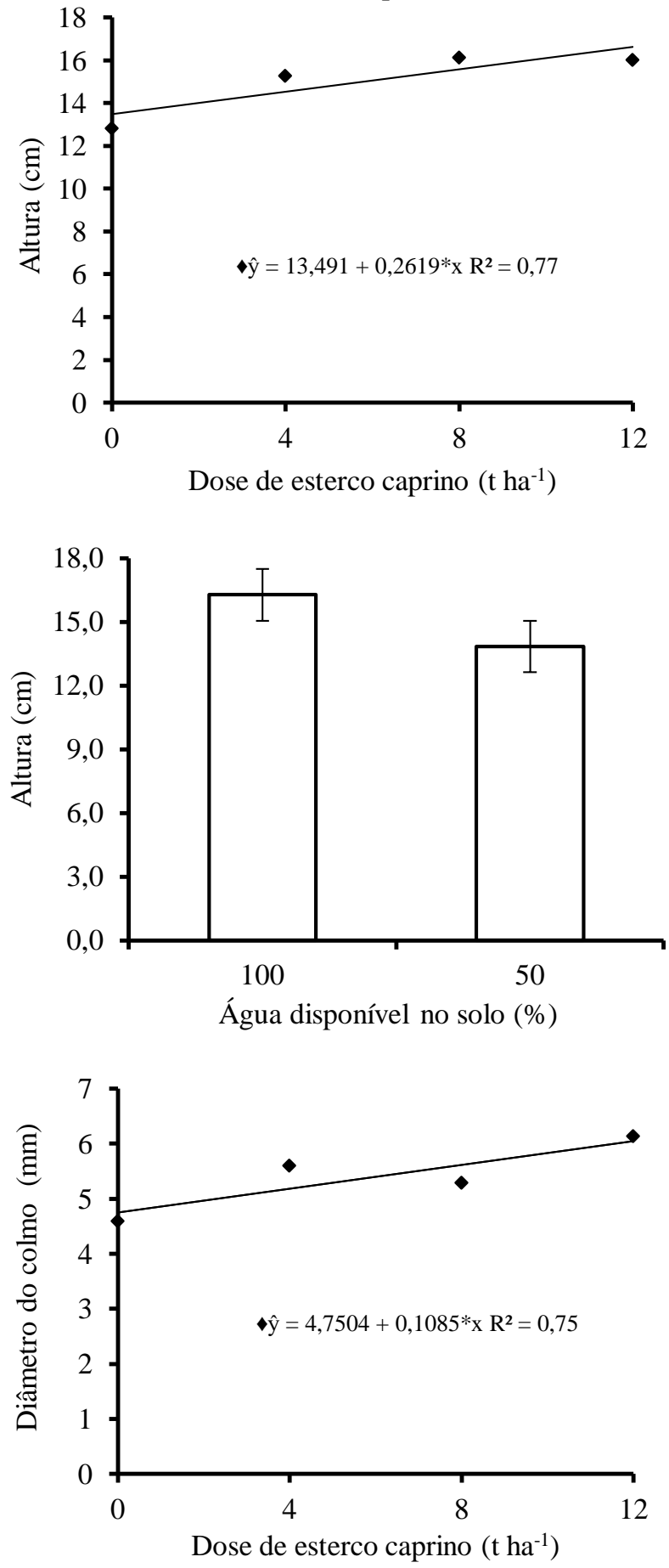

Em relação a massa seca da parte aérea (MSPA) e massa seca total (MST) que estão representados na Figura (2A e C), constatou-se comportamento linear crescente em função das doses de esterco caprino que foram aplicadas. Nessas varáveis constatou-se um incremente unitário de 0,0389 g de MSPA e de $0,0420 \mathrm{~g}$ de MST, que corresponde ao incremento de 0,47 e $0,50 \mathrm{~g}$, respectivamente ao compara a maior $\left(12 \mathrm{t} \mathrm{ha}^{-1}\right)$ e a menor dose estudada (Figura 2A e C). Resultados semelhantes foram verificados por Souza et al. (2016) avaliando o acúmulo de massa seca de plantas de milho sob déficit hídrico e doses de cama de frango. Os autores observaram comportamento linear do acúmulo de massa seca das plantas de milho em função do aumento da doses de cama de frango.
Esse incremento no acúmulo de massa seca das plantas de milho, em resposta adição do esterco caprino está diretamente relacionado ao fornecimento de nutrientes, haja vista, que a aplicação de matéria orgânica contribui para elevação da capacidade de troca de cátions (CTC) do solo e fornece micronutrientes Zandonadi et al. (2014), favorecendo maior e melhor aproveitamento dos nutrientes por parte dos vegetais.

Figura 2. Massa seca da parte aérea-MSPA (A), raízes-MSR (B) e total-MST (C) de plantas de milho sob doses de esterco caprino.
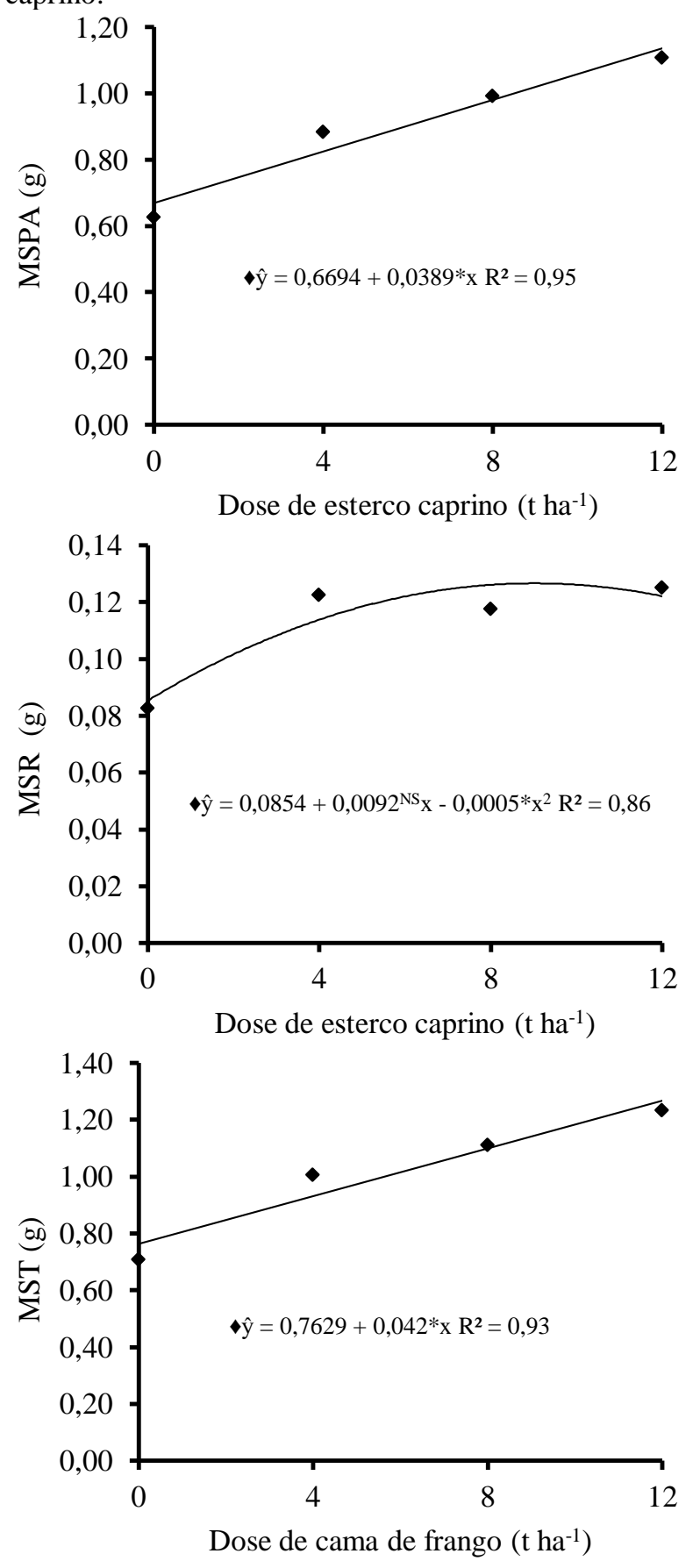

Na Figura 2B observa-se a massa seca da raiz (MSR). Nota-se comportamento quadrático em função das doses de esterco caprino aplicadas. A dose de 9,2 $\mathrm{t} \mathrm{ha}^{-1}$ proporcionou um acúmulo de MSR na ordem de $0,13 \mathrm{~g}$. Apesar da $\mathrm{AD}$ não ter influenciado na MSR, acredita-se que 
houve algum efeito fitotóxico do adubo nas raízes, prejudicando seu crescimento. Mesquita et al. (2017) avaliando níveis de água e adubação orgânica na MSR da mamoneira, concluíram que a quantidade de água pode influenciar a concentração de esterco na zona radicular, podendo causar efeito deletério nas raízes. Sá et al. (2017) encontraram resultados parecidos na MSR avaliando a depleção de água e composição do substrato para produção de mudas de melancia.

\section{CONCLUSÕES}

A redução de $50 \%$ de água no solo não exerce impactos negativo sobre a emergência e crescimento inicial das plantas de milho AG1051.

A dose de esterco caprino de $12 \mathrm{t} \mathrm{ha}^{-1}$ promoveu o maior crescimento e acúmulo de massa seca das plantas de milho.

\section{REFERÊNCIAS}

BERGONCI, J. I.; BERGAMASCHI, H.; BERLATO, M. A.; SANTOS, A. O. Condutância foliar como um indicador de déficit hídrico em milho. Revista Brasileira de Agrometeorologia, v.8, n.1, p.27-34, 2000.

BRUGNARA, E. C. Cama de aviário em substratos para mudas de maracujazeiro-amarelo. Revista Brasileira de Agroecologia, v.9, n.3, p.21-30, 2014.

CASTRO, C. N. A agricultura no Nordeste brasileiro: oportunidades e limitações ao desenvolvimento. Boletim regional, urbano e ambiental, v.8, n.2, p.77-89, 2013.

COSTA, A. S. V. J.; RUFINI, J. C. M.; SILVA, M. B. S.; GALVÃO, E. R.; RIBEIRO, J. M. O. Efeito do resíduo de celulose e esterco no solo sobre o desenvolvimento do milho (Zea mays) e feijão (Phaseolus vulgaris). Revista Ceres, v.54, n.314, p.339-344, 2007.

EMBRAPA. Centro Nacional de Pesquisa de Solos. Manual de métodos de análise do solo. 3 ed. Rio de Janeiro, 2011, 230 p. (Embrapa-CNPS. Documentos, 132).

FERRARI, E.; PAZ, A.; SILVA, A. C. Déficit hídrico no metabolismo da soja em semeaduras antecipadas no mato grosso. Nativa, v.03, n.01, p.67-77 2015.

FERREIRA, A. O.; SÁ, J. C. M.; NASCIMENTO, C. G.; BRIEDIS, C.; RAMOS, F. S. Impacto de resíduos orgânicos de abatedouro de aves e suínos na produtividade do feijão na região dos campos gerais - PR - Brasil. Revista Verde de Agroecologia e Desenvolvimento Sustentável, v.5, n.4, p.15$21,2010$.

FERREIRA, D. F. Sisvar: a computer statistical analysis system. Ciência e Agrotecnologia, v.35, n.6, p.1039-1042, 2011.

GALVÃO, S. R. S.; SALCEDO, I. H.; OLIVEIRA, F. F. Acumulação de nutrientes em solos arenosos adubados com esterco bovino. Pesquisa Agropecuária Brasileira, v.43, n.1, p.99- 105, 2008.
KIEHL, E. J. Manual de edafologia. São Paulo, Agronômica Ceres, 1979. 262p.

LERAYER, A. Guia do milho: tecnologia do campo a mesa. Conselho de Informações sobre Biotecnologia. 2006. 15 p.

MELO, R. F.; BRITO, L. T. L.; PEREIRA, L. A.; ANJOS, J. B. Avaliação do uso de adubo orgânico nas culturas de milho e feijão caupi em barragem subterrânea. Revista Brasileira de Agroecologia, v.4, n.2, p.1264-1267, 2009.

MESQUITA, E. F.; SÁ, F. V. S.; SUASSUNA, C. F.; SOUZA, F. M.; ANDRADE, L. R.; SANTOS, G. J. F. Fitomassa e eficiência do uso da água da mamoneira BRS Gabriela irrigada sob adubação orgânica. Revista Brasileira de Agricultura Irrigada v.11, n.3, p.1458-1467, 2017.

PEREIRA, R. F.; LIMA, A. S., MAIA FILHO, F. C. F.; CAVALCANTE, S. N.; SANTOS, J. G. R.; ANDRADE, R. Produção de feijão vigna sob adubação orgânica em ambiente semiárido. Agropecuária Científica no Semiárido, v.9, n.2, p.27-32, 2013.

SÁ, F. V. S.; MESQUITA, E. F.; SOUZA, F. M.; MESQUITA, S. O.; PAIVA, E. P.; SILVA, A. M. Depleção de água e composição do substrato na produção de mudas de melancia. Revista Brasileira de Agricultura Irrigada v.11, n.3, p.1398-1406, 2017.

SCHITTENHELM, S. Effect of drought stress on yield and quality of maize/sunflower and maize/sorghum intercrops for biogas production. Journal of Agronomy and Crop Science, v.196, n.4, p.253-261, 2010.

SILOTO, R. C. Danos e biologia de Spodoptera frugiperda (J. E. Smith, 1797) (Lepidoptera: Noctuidae) em genótipos de milho. 2002. 93 f. Dissertação (Mestrado em Entomologia) Escola Superior de Agricultura Luiz de Queiroz, Universidade de São Paulo, Piracicaba, 2002.

SOUZA, F. M. S.; LIMA, E. C. S.; SÁ, F. V. S.; SOUTO, L. S.; ARAÚJO, J. E. S.; PAIVA, E. P. Doses de esterco de galinha e água disponível sob o desenvolvimento inicial do milho. Revista Verde de Agroecologia e Desenvolvimento, v.11, n.5, p.64-69, Edição especial, 2016.

STEVENSON, E. J. Humus chemistry: genesis, composition, reactions. New York, NY: John Wiley \& Sons., 1982. 443p.

SCHUAB, S. R. P.; BRACCINI, A. L.; FRANÇA NETO, J. B.; CARLOS ALBERTO SCAPIM, C. A.; MESCHEDE, D. K. Potencial fisiológico de sementes de soja e sua relação com a emergência das plântulas em campo. Acta Scientiarum Agronomy, v.28, n.4, p.553-561, 2008.

ZANDONADI, D. B.; SANTOS, M. P.; MEDICI, L. O.; SILVA, J. Ação da matéria orgânica e suas frações sobre a fisiologia de hortaliças. Horticultura Brasileira, v.32, n.1, p.14-20, 2014. 